\title{
MICROBE-FILCHING AND FINGERPRINTING
}

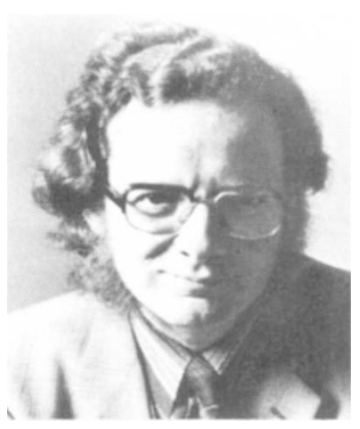

D esourceful but dishonest miRcrobe hunters are said to exploit a variety of stratagems in filching prized organisms away from their competitors' laboratories. At a recent Warwick University symposium (devoted, appropriately enough, to entrepreneurship in biotechnology) I heard three different allegations of microbial buccaneering, each more ingenious than the last. Most plausible was the surreptitious planting and later removal of Sellotape from the top of a centrifuge likely to be seeded by desirable bacteria.

According to another informant, in Munich last year, one individual even employed confectionery as a hastily improvised attractant for this purpose. Presented with an unexpected opportunity to sample potentially rewarding surfaces inside a rival biotechnologist's cold-room, he had whipped out a slug of chewing gum and applied it to the under-side of a nearby bench. Plopped into nutrient broth back at his home base and cultured for 24 hours, the gum yielded intriguingly mixed flora reflecting vividly the varied activities being pursued in the cold-room. The visitor was particularly interested to find unambiguous evidence of one research interest which his host had hotly denied two days earlier.

For obvious reasons, most stories of this sort are off-therecord. Some may be apocryphal. Others are undoubtedly true. My favorite was very much on the record in Perspectives in Biology and Medicine (25:263, 1982). Discussing the general issue of open information in science, Alexander Faberge reported a case where attempted secrecy proved to be directly counterproductive in the field of molecular biology. "A worker wrote to another laboratory asking for a lambda phage which had recently been described from there," wrote Dr. Faberge. "A letter came back, refusing the phage and making it clear that the worker making the request was not a proper member of the club. Despite this obvious lack of qualification to receive the gift, the miscreant had the effrontery to realize that such phages get around in laboratories, and he succeeded most elegantly in culturing the lambda phage by incubating the refusal letter itself."

Contrasting with such subterfuge is a more honorable and historic plan for the clandestine spiriting away of precious microorganisms. In 1941, when Howard Florey and his colleagues in Oxford were on the verge of turning Alexander Fleming's earlier discovery of penicillin into the first real wonder drug, the war with Germany was at a critical point. Invasion seemed imminent. Like many other families, the Floreys were sending their children to Canada for safety. And the development of penicillinpoised tantalizingly on the brink of spectacular successseemed to be in jeopardy. So that summer, the team resolved to destroy everything relating to their momentous project if and when enemy forces landed. The sole exception was the Oxford strain of Penicillium notatum, which Florey, Norman Heatley, and others smeared over their clothes. Should they escape, patches of material from coats and trousers could be subcultured to retrieve the life-saving mould.

Today's microbial pirates are motivated by less noble motives. And they have to contend with some formidable obstacles-physical containment, clean rooms, fanatical sterility, eagle-eyed secretaries. Yet the stakes are correspondingly higher too. Pedigree strains and elite recombinants are revered as never before. Now that such invaluables can be patented, microbiological theft is becoming an occupation almost as enticing to the criminal fraternity as that of arms smuggling. What can be done about it?

One answer is being touted just now by BioTechnica Ltd. based in Cardiff, Wales. Although still in the early stages of evaluating the commercial significance of what it calls "fingerprinting for verification," the company believes that this method will allow organisms to be compared with such rigorous resolution as to settle conclusively allegations about the origin of disputed strains. BioTechnica has launched a service through which it will compare "suspect" and "reference" samples sent by clients, but will also make the technique available for use inhouse by other companies.

Evolved by a team under J. H. Slater, BioTechnica's research director who is also professor of applied microbiology at the University of Wales Institute of Science and Technology, the new test will help in identifying eukaryotes as well as prokaryotes. After radio-labelling, DNA from the questionable organism is fragmented and mixed with that from its legitimate counterpart. The amount of hybridization then indicates the degree of affinity between the two sequences, and thus the similarity between the parent organisms. For prokaryotes, Professor Slater says, it is both simple and experimentally cheap to secure confidence limits of one in $10^{60}$-that figure being the remote chance of claiming erroneously an identity or difference between two strains when the opposite is true. BioTechnica believes that these levels of assurance will be sufficiently high to allow a company to make "unequivocal claims to the ownership of its own living material." In the case of eukaryotes, the confidence limits are lower but will still be better than one in $10^{15}$.

The applications now being pursued include protection of novel inoculants in the agricultural and food industries; comparison of plant cell tissue culture lines and the plants grown from them; matching of new isolates of antibioticproducers with previous, commercially successful organisms; and the cross-comparison of strains independently deposited in culture collections. BioTechnica is also patenting the allied technique of "fingerprinting for quality control," to ensure that genotypes are being maintained and cell lines breeding true to type.

Sellotape and chewing gum have many excellent uses. But time could be running out for the one their makers least intended.

Bernard Dixon, Ph.D., is contributing editor of Bio/Technology. 